40. B. D. Davis, Proc. Natl. Acad. Sci. U.S.A. 86, 5005 (1989).

41. F. J. Ryan, Genetics 40, 726 (1955); J. Gen. Microbiol. 21, 530 (1959)

42. E. G. Leigh, Jr., Genetics (suppl.) 73, 1 (1973); L. Chao and E. C. Cox, Evolution 37, 125 (1983); B D. Robertson and T. F. Meyer, Trends Genet. 8 422 (1992).

43. B. C. Lampson et al., Science 243, 1033 (1989)

44. These repair systems distinguish template DNA from newly synthesized DNA by the new DNA's unmethylated state. Thus, these systems can resolve DNA mismatches in favor of the unmutated allele. Other mismatch repair systems are not meth yl-directed and are presumably error prone (45).

45. S. R. Kushner, in Escherichia coli and Salmonella typhimurium, F. C. Neidhardt, Ed. (American Society for Microbiology, Washington, DC, 1987) chap. 61

46. L. Boe, Mol. Microbiol. 4, 597 (1991).

47. B. G. Hall, New Biologist 3, 729 (1991).

48. F. M. Stewart et al., Genetics 124, 175 (1990)

49. E. M. Witkin, ibid. 32, 221 (1947).

50. N. Symonds, Nature 337, 119 (1989).

51. J. E. Mittler and R. E. Lenski, ibid. 344, 173 (1990)

52. P. L. Foster, J. Bacteriol. 174, 1711 (1992)

53. R. E. Lenski, Genetics 107, 1 (1984).

54. The lack of correspondence between numbers of mutants and mutational events is especially problematic in liquid media, owing to the physica dispersion of mutants that are identical by descent.

55. Cairns reported that he was unable to reproduce our experiments, whereas we responded that Shapiro, who generated the original unexpected results (36), had done so (56). Drake $(57$, p. 133$)$ suggested that "this dispute remains moot pending unlikely investigations into obscure variables like water quality and shaker speed." But we think it is unlikely that a phenomenon that purports to challenge a fundamental principle depends on ill-defined interactions with obscure variables.

56. J. Cairns, Nature 345, 213 (1990); J. E. Mittler and R. E. Lenski, ibid., p. 213.
57. J. W. Drake, Annu. Rev. Genet. 25, 125 (1991)

58. S. A. Benson et al., Genetics 129, 647 (1991).

59. Hall (14) tested only one independent mutant, but the relevant issue is the enrichment of a phenotypically defined class of mutants, which requires only that some members of that class have an advantage. Also, no analysis was made of the inferential power of the experiment (the amount of enrichment that might have occurred but gone undetected). Perhaps most critically, the mutant population was treated with an antibiotic, which may have inhibited its growth.

60. J. E. Mittler and R. E. Lenski, Nature 356, 446 (1992).

61. Population genetic theory does allow mutation rates to evolve (42). For example, selection may favor alleles that increase or decrease mutation rates, depending on the constancy of the environment. The possibility that mutation rates are subject to selection, however, is quite different from the claim that specific mutational events occur more often when they are advantageous.

62. For example, Drake $(57$, p. 135$)$ believes that "work to date well supports the conclusion that adaptive bacterial mutations can occur, singly or doubly as required, at sharply increased rates under selective conditions."

63. M. Demerec, Proc. Natl. Acad. Sci. U.S.A. 34, 425 (1945); J. Bacteriol. 56, 63 (1948); F. J. Ryan, J. Gen. Microbiol. 7, 69 (1952); Nature 169, 882 (1952); P. Armitage, J. Roy. Stat. Soc. Ser. B 14, 1 (1952).

64. We express our gratitude to the many colleagues who have discussed and debated these issues with us. We thank A. Bennett, A. Campbell, J. Coyne, M. Feldgarden, L. Forney, P. Foster, G. Kreisel, M. Lenski, B. Levin, I. Molineux, J. Mongold, M. Rose, M. Schmid, P. Sniegowski, L Snyder, D. Thaler, M. Travisano, and two anonymous referees for helpful comments on our paper and $M$. Malavasic for sharing a paper in press. This work was supported by NSF grant DEB 9249916 to R.E.L.

\title{
Atmospheric Lifetimes of Long-Lived Halogenated Species
}

\author{
A. R. Ravishankara, S. Solomon, A. A. Turnipseed, \\ R. F. Warren*
}

The atmospheric lifetimes of the fluorinated gases $C_{4}, C_{2} F_{6}, c-C_{4} F_{8},\left(C F_{3}\right)_{2} c-C_{4} F_{6}$, $\mathrm{C}_{5} \mathrm{~F}_{12}, \mathrm{C}_{6} \mathrm{~F}_{14}, \mathrm{C}_{2} \mathrm{~F}_{5} \mathrm{Cl}, \mathrm{C}_{2} \mathrm{~F}_{4} \mathrm{Cl}_{2}, \mathrm{CF}_{3} \mathrm{Cl}$, and $\mathrm{SF}_{6}$ are of concern because of the effects that these long-lived compounds acting as greenhouse gases can have on global climate. The possible atmospheric loss processes of these gases were assessed by determining the rate coefficients for the reactions of these gases with $\mathrm{O}\left({ }^{1} \mathrm{D}\right), \mathrm{H}$, and $\mathrm{OH}$ and the absorption cross sections at 121.6 nanometers in the laboratory and using these data as input to a two-dimensional atmospheric model. The lifetimes of all the studied perfluoro compounds are $>2000$ years, and those of $\mathrm{CF}_{3} \mathrm{Cl}, \mathrm{CF}_{3} \mathrm{CF}_{2} \mathrm{Cl}$, and $\mathrm{CF}_{2} \mathrm{ClCF}_{2} \mathrm{Cl}$ are $>300$ years. If released into the atmosphere, these molecules will accumulate and their effects will persist for centuries or millennia.

Most of the chemicals released into the atmosphere as a result of natural processes or human activities are converted to other forms or are completely removed from the atmosphere within a few years. This happens because most of these molecules react with the major oxidants in the atmosphere or are photolyzed at wavelengths greater than $190 \mathrm{~nm}$. A few species, however, exhibit very low reactivities. We might ask: What happens to molecules that do not react with most of the oxidants in the stratosphere and the troposphere? The answer to this question is not only of fundamental interest but also of practical significance. If an industrially produced chemical has an atmospheric lifetime of a few thousand years or more, it would accumulate in the atmosphere for times longer than human civilization.

Fully fluorinated organic compounds are chemically very inert and fall into the above class of unusually long-lived atmospheric constituents. Even when some of the fluorine is replaced by chlorine, the stability remains high. These gases will be efficient greenhouse gases and, because of their stability, they will persist in the atmosphere. The atmospheric lifetime of each of these species, a measure of its accumulation tendency, is of particular importance because it is used in the calculation of the global warming potential (GWP), an index of global climate impacts used in policy decisions. The GWP depends on the infrared absorption spectrum and the lifetime of atmospheric gases [see (1)]. The GWP of $\mathrm{CF}_{4}$, for example, is estimated (2) to be at least as large as that for chlorofluorocarbon11 (CFC-11 or $\mathrm{CFCl}_{3}$ ).

Because of their stability and thermophysical properties, these long-lived molecules have been and are being considered for various industrial applications, including fire extinguishing, foam blowing, and refrigeration. The simplest molecule in this class, $\mathrm{CF}_{4}$, is also a by-product of aluminum production. Three such compounds, $\mathrm{CF}_{4}$ (3-5), $\mathrm{C}_{2} \mathrm{~F}_{6}(3,5)$, and $\mathrm{SF}_{6}(6)$, have been observed in the atmosphere. The observed vertical profiles of these molecules are consistent with atmospheric lifetimes of hundreds of years. All these molecules are solely anthropogenic (human-made).

Cicerone (7) was the first to consider what could happen to $\mathrm{CF}_{4}$ in the atmosphere. He concluded that this molecule is nearly inert in the stratosphere and troposphere and has a lifetime of more than 10,000 years. He suggested that a likely process that could destroy this molecule would be photolysis by solar Lyman- $\alpha$ radiation at $121.6 \mathrm{~nm}$. A window in oxygen absorption at this wavelength coupled with a larger incoming flux make absorption of Lyman- $\alpha$ radiation a potentially important mesospheric loss process for tightly bound molecules [such as $\mathrm{H}_{2} \mathrm{O}(8)$ ]. As far as we know, the atmospheric fate and lifetimes of the other fully fluorinated compounds have not been investigated.

We have examined the possible paths by

The authors are with the National Oceanic and Atmospheric Administration Aeronomy Laboratory, Boulder, $\mathrm{CO} 80303$, and Cooperative Institute for Research in Environmental Science, University of Colorado, Boulder CO 80309 . A R Ravishankara is also affiliated with the Department of Chemistry and Biochemistry, University of Colorado, Boulder, CO 80309.

*Present address: Centre for Environmental Technology, Imperial College of Science, Technology, and Medicine, 48 Prince's Gardens, London SW7 2PE, United Kingdom. 
which ten compounds, $\mathrm{CF}_{4}, \mathrm{C}_{2} \mathrm{~F}_{6}, \mathrm{c}-\mathrm{C}_{4} \mathrm{~F}_{8}$, $\left(\mathrm{CF}_{3}\right)_{2} \mathrm{c}-\mathrm{C}_{4} \mathrm{~F}_{6}$ (perfluoro 1,2-dimethyl-cyclobutane), $\mathrm{C}_{5} \mathrm{~F}_{12}, \mathrm{C}_{6} \mathrm{~F}_{14}, \mathrm{C}_{2} \mathrm{~F}_{5} \mathrm{Cl}, \mathrm{C}_{2} \mathrm{~F}_{4} \mathrm{Cl}_{2}$, $\mathrm{CF}_{3} \mathrm{Cl}$, and $\mathrm{SF}_{6}$, may be destroyed in the atmosphere. We have explicitly considered the following pathways for their destruction: (i) photolysis by Lyman- $\alpha$ radiation (121.6 $\mathrm{nm})$, (ii) reaction with $\mathrm{O}\left({ }^{1} D\right)$, (iii) reaction with $\mathrm{OH}$, (iv) reaction with $\mathrm{H}$ atoms, and (v) destruction by thermolysis or reactions at high temperatures. In addition, on the basis of earlier work, we have estimated that the removal rates for most of these compounds due to lightning, ion reactions in the mesosphere, and dissolution in liquid water are unimportant. We have also estimated (on the basis of analogy to the molecules studied here) the atmospheric lifetime of $\mathrm{C}_{4} \mathrm{~F}_{10}$. In this article, we use these approaches to estimate atmospheric lifetimes of these compounds and discuss the implications of our findings to the GWP and other effects.

\section{Reaction Rate Coefficients and Absorption Cross Sections}

Many of the reactions we studied are slow, and some of the measured absorption cross sections are extremely small. It is difficult to measure such parameters accurately. Even with a great deal of effort and attention to sources of systematic errors, we were able to obtain only upper limits for some of the parameters. Yet, these upper limits are sufficient to place firm constraints on the lifetimes.

We measured the $O\left({ }^{1} D\right)$ reaction rate coefficients using the apparatus and methodology described by Warren et al. (9). We determined the rate coefficient for the removal of $O\left({ }^{1} D\right)$ and the fraction of $O\left({ }^{1} D\right)$ that is quenched to $O\left({ }^{3} P\right)$ by a given compound. From these data, we derived the rate coefficient for the reactive removal of $\mathrm{O}\left({ }^{1} D\right)$. We assume that the rate coefficient for the reactive removal of $O\left({ }^{1} D\right)$ is the same as the rate coefficient for the removal of the compound, which is needed for calculations of the lifetimes. The results (Table 1) show that the reactions of $O\left({ }^{1} D\right)$ with perfluoro compounds are orders of magnitude slower than those with hydrocarbons, partially halogenated hydrocarbons, and even perchloro compounds (10). Furthermore, even the observed $O\left({ }^{1} D\right)$ loss is largely due to a physical quenching to
$O\left({ }^{3} \mathrm{P}\right)$ rather than to a chemical reaction. In Table 1 we have also listed rate coefficients for the reactions of $\mathrm{O}\left({ }^{1} D\right)$ with $\mathrm{CF}_{4}$, $\mathrm{CF}_{3} \mathrm{Cl}$, and $\mathrm{CF}_{2} \mathrm{ClCF}_{2} \mathrm{Cl}$ reported by other investigators. The presence of undetected small impurities in our samples of $\mathrm{CF}_{4}$ and $\mathrm{SF}_{6}$ could have led to the apparent rate coefficients. Therefore, our values should be considered upper limits. In all of the modeling calculations we used the values reported in Table 1 .

The apparatus that we used for studying $\mathrm{H}$ atom reactions was the same as that used for studying $O\left({ }^{1} D\right)$ reactions. We measured the temporal profiles $(11,12)$ of $\mathrm{H}\left({ }^{2} \mathrm{~S}\right)$ produced by the $222-\mathrm{nm}$ pulsed laser photolysis of $\mathrm{CH}_{3} \mathrm{SH}$ in the presence of various concentrations of the fluorocarbons at 298 $\mathrm{K}$. From the observed increase in the firstorder decay rate constant for $\mathrm{H}$ atoms in the presence of the fluorocarbon over those in their absence, the rate coefficients for the reaction were evaluated. The results (Table 1) show that the reactions of $\mathrm{H}\left({ }^{2} S\right)$ with perfluorocarbons are extremely slow. The upper limit for the rate coefficient for the reaction of $\mathrm{H}$ with $\mathrm{CF}_{4}$ is consistent with the expected activation energy for this re-
Table 1. Summary of rate coefficients and Lyman- $\alpha$ absorption cross sections measured during this study. Results from earlier studies on $O\left({ }^{1} D\right)$ reactions are also shown. The numbers in the parentheses are the exponents of 10 ; for example, $1.0(-11)$ is $1.0 \times 10^{-11}$. All rate coefficients are in units of $\mathrm{cm}^{3}$ molecule ${ }^{-1} \mathrm{~s}^{-1}$.

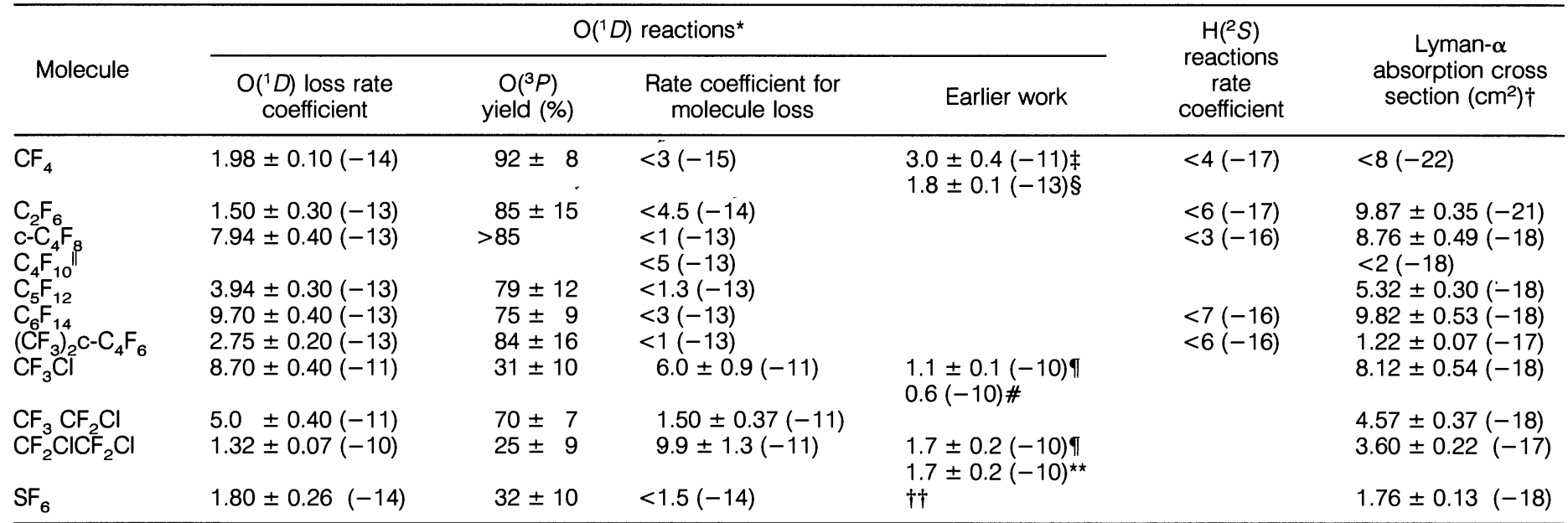

*Some of the rate coefficients reported here should be considered upper limits. See below. The rate coefficient for the loss of the molecule was calculated from the measured rate coefficient for the loss of $O\left({ }^{1} D\right)$ and the fraction of $O\left({ }^{1} D\right)$ quenched to $\mathrm{O}\left({ }^{3} P\right)$. †As a test case, we also measured the absorption cross section of $\mathrm{O}_{2}$ as a function of pressure. The measured absorption cross sections extrapolated to zero pressure yield a value of $\sigma_{0}=(1.04 \pm 0.04) \times 10^{-20} \mathrm{~cm}^{2}$, in excellen agreement with the values of Carver et al. (23). The measured rate of variation of the cross section with pressure, $d \sigma / d p$, was $(2.0 \pm 0.2) \times 10^{-23} \mathrm{~cm}^{2}$ torr $^{-1}$, also in excellent agreement with the value obtained by Carver et al. $¥$ The reason for the higher value obtained by Fletcher and Husain (24) is not clear. The presence of impurities in their sample may not be the cause because very large amounts of impurities (a few percent of very reactive compounds) would be needed to account for such a large measured value. Even the much lower rate coefficients measured here could be influenced by the presence of impurities. Therefore, our values are to be considered upper limits. \$Force and Wiesenfeld (25) also determined that essentially all of the interaction proceeded through physical quenching. Thus, their rate coefficient for the reactive loss of $\mathrm{O}\left({ }^{1} D\right)$ with $\mathrm{CF}_{4}$ would be essentially zero. Even the overall $O\left({ }^{1} D\right)$ loss rate measured by Force and Wiesenfeld may be too high because of the presence of $\mathrm{O}_{2}$ in their $\mathrm{CF}_{4}$ samples. Therefore, our results are in good agreement with those of Force and Wiesenfeld. $\quad$ We estimated the rate coefficient for the reactive loss of $\mathrm{C}_{4} \mathrm{~F}_{10}$ with $\mathrm{O}\left({ }^{1} D\right)$ and its absorption cross sections by comparing the molecules with the others listed in the table. These estimates were chosen to minimize its lifetime and, hence, yield a lower limit for its atmospheric lifetime. IFletcher and Husain (24) measured the rate coefficient to be larger by a factor of $\sim 2.2$ than that shown here. It has been corrected for the presence of a systematic error in their measurements [DeMore et al. (10); Davidson et al. (26)]. This value is in reasonably good agreement with those reported for the loss of $O\left({ }^{1} D\right)$ in the present work. \#Jayanty et al. (27) reported the rate coefficient for the loss of $\mathrm{CF}_{3} \mathrm{Cl}$ by reaction with $O\left({ }^{1} D\right)$ to be $6.0 \times 10^{-11} \mathrm{~cm}^{3}$ molecule ${ }^{-1} \mathrm{~s}^{-1}$, in excellent agreement with our value for the loss of $\mathrm{CF}_{3} \mathrm{Cl}$ in this reaction. TThe value of $6.0 \times 10^{-11} \mathrm{~cm}^{3}$ molecule $e^{-1} \mathrm{~s}^{-1}$ was calculated using the currently recommended value for the rate coefficient for the reaction of $\mathrm{O}\left({ }^{1} D\right)$ with $\mathrm{N}_{2} \mathrm{O}$ [DeMore et al. (10)] and the rate constant ratio measured by Jayanty et al.]. ${ }_{\star}{ }^{\circ}$ Pitts et al. (28) reported the ratio for the rate coefficient for the loss of $\mathrm{CF}_{2} \mathrm{ClCF}_{2} \mathrm{Cl}$ and $\mathrm{N}_{2} \mathrm{O}$ by reaction with $\mathrm{O}\left({ }^{1} D\right)$ to be $1.5 \pm 0.2$; this ratio leads to a rate coefficient for the loss of $\mathrm{CF}_{2} \mathrm{CICF}_{2} \mathrm{Cl}$ by the $\mathrm{O}\left({ }^{1} D\right)$ reaction of $1.7 \times 10^{-10} \mathrm{~cm}^{3}$ molecule ${ }^{-1} \mathrm{~s}^{-1}$, higher by a factor of 2 than that measured here. ††Davidson et al. (26) used many-torr $\mathrm{SF}_{6}$ as a buffer gas in their studies of $O\left({ }^{1} D\right)$ reactions with no apparent change in the loss rate of the excited $O$ atoms. They did not specifically report a rate coefficient for the $\mathrm{O}\left({ }^{1} D\right)+\mathrm{SF}_{6}$ reaction, but their observations are consistent with the small rate coefficient reported here. 
action of at least $10 \mathrm{kcal} \mathrm{mol}^{-1}$. These rate coefficients will be lower at the typical atmospheric temperatures.

We did not explicitly measure the rate coefficients for the reaction of $\mathrm{OH}$ with $\mathrm{SF}_{6}$. However, we have used $\mathrm{SF}_{6}$ as a bath gas in $\mathrm{OH}$ reaction studies. The first-order loss rate coefficients for $\mathrm{OH}$ loss in these experiments at $\sim 1$ atm pressure were usually the same as those in $\mathrm{N}_{2}$. On the basis of this observation, we confidently place an upper limit of $\leq 5 \times 10^{-19} \mathrm{~cm}^{3}$ molecule ${ }^{-1} \mathrm{~s}^{-1}$ for the reaction of $\mathrm{OH}$ with $\mathrm{SF}_{6}$ at temperatures less than $298 \mathrm{~K}$. The upper limit for the rate coefficient for $10^{-18} \mathrm{~cm}^{3}$ molecule ${ }^{-1} \mathrm{~s}^{-1}$. The reactions of $\mathrm{OH}$ with other compounds were not studied. On the basis of a lack of thermodynamically allowed metathesis-reactive pathways, we estimate that the rate coefficients for all of the $\mathrm{OH}$ reactions with the compounds we studied, including $\mathrm{CF}_{4}$, are $\leq 1 \times 10^{-18} \mathrm{~cm}^{3}$ molecule ${ }^{-1} \mathrm{~s}^{-1}$ at atmospheric temperatures.

Because Lyman- $\alpha$ radiation lies in the vacuum ultraviolet (VUV) region of the electromagnetic spectrum, normal UV spectrometers cannot be used for the measurements of the absorption cross sections at $121.6 \mathrm{~nm}$. The Lyman- $\alpha$ radiation was produced by the passage of a mixture of $1.2 \% \mathrm{H}_{2}$ in ultrahigh purity $\mathrm{He}$ at 6 to 10 torr through a microwave discharge. This radiation was passed through a $10-\mathrm{cm}$ absorption cell and into a $0.2-\mathrm{m}$ VUV monochromator. The $121.6-\mathrm{nm}$ radiation exiting from the monochromator was detected by a solar blind photomultiplier the reaction of $\mathrm{OH}$ with $\mathrm{CF}_{4}$ was $<2 \times$

tube and its current measured with a digital picoammeter. The spectral resolution of the monochromator was either 0.2 or $0.05 \mathrm{~nm}$. (As expected, there was no difference in the measured cross section when the resolution was altered.) The pressure in the absorption cell was measured by a capacitance manometer (using either a 10 - or 1000 -torr head). The absorptions due to various amounts of the test gas were measured, and the absorbances were found to vary linearly with gas concentration in the absorption cell. Typically, the absorbances were measured at ten concentrations of the gas and were plotted against these concentrations. The absorption cross sections were obtained from the slope of such plots, which were always linear and passed through the origin (within the error of the measurements). The absorption cross sections obtained (Table 1) increase with the size of the perfluorocarbon and appear to be larger for the cyclic compounds than for the linear compounds. The main sources of uncertainties in these determinations are those in pressure measurements and in the amount of absorbing impurities. The latter problem is likely to be the limiting factor in the measured cross section of $\mathrm{CF}_{4}$. The impurity must be one that absorbs at 121.6 $\mathrm{nm}$ but does not react rapidly with $\mathrm{O}\left({ }^{1} D\right)$. Because of uncertainty about the amounts of impurities in our sample, we report an upper limit for this cross section. The measured upper limit is sufficient for the atmospheric lifetime calculations, because absorption at $121.6 \mathrm{~nm}$ is unlikely to be the principal process that removes this

Table 2. Calculated lifetimes, $\tau$, in years for various processes, the best estimate, and the lowest estimate for some fully fluorinated compounds and a few CFCs. The numbers in parentheses are the exponents of 10; for example 1.0 (4) is $1.0 \times 10^{4}$. We obtained the lower limit by assuming that removal by combustion has the limit shown in the $\tau$ (combust) column and the other processes are as rapid as possible (see text).

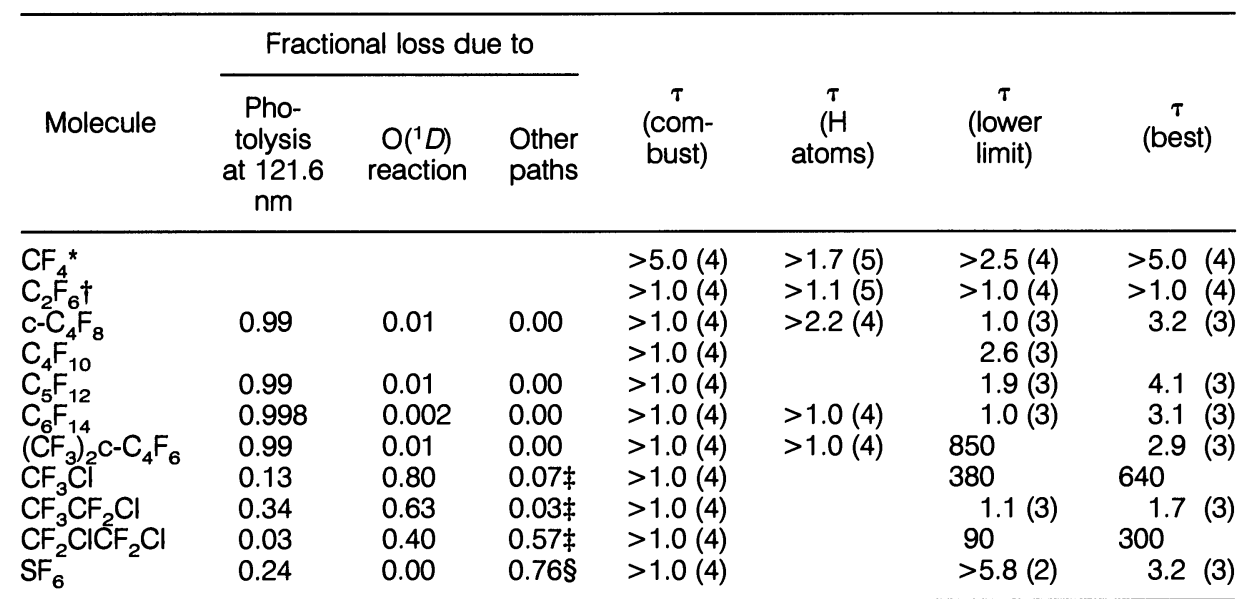

*The computed lifetime for loss by photolysis at $121.6 \mathrm{~nm}$, the only recognized loss process, is $>6.2 \times 10^{6}$ year. We obtained the lower limit by assuming that the $\mathrm{OH}$ reaction proceeds at the upper limit given in the text and that combustion contributes at the upper limit shown in the table. †The computed lifetime for loss by photolysis at $121.6 \mathrm{~nm}$ and reaction with $\mathrm{O}\left({ }^{1} D\right)$ is $4.5 \times 10^{5}$ years. $\quad$ Photolysis by ultraviolet radiation from 180 to $220 \mathrm{~nm}$; absorption cross sections from Gillotay and Simon (29). \$Reaction with free electrons in the mesosphere.

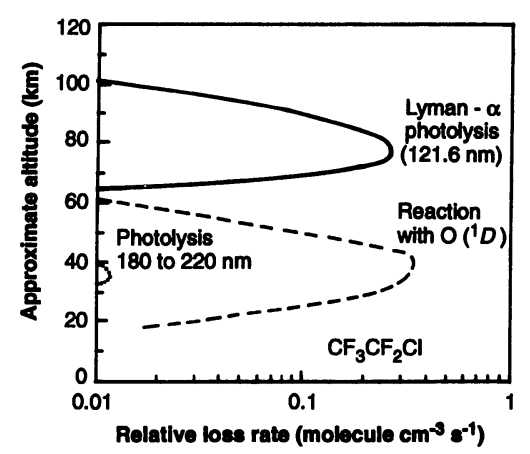

Flg. 1. Relative noontime loss rates at midlatitude in the summer for $\mathrm{CFC}-115\left(\mathrm{CF}_{3} \mathrm{CF}_{2} \mathrm{Cl}\right)$ due to photolysis at $121.6 \mathrm{~nm}$ (solid line), reaction with $O\left({ }^{1} D\right)$ (dashed line), and photolysis in the 180- to $220-\mathrm{nm}$ reaction (dotted line) as functions of altitude. For this molecule, the losses due to 121.6-nm photolysis at $\sim 75 \mathrm{~km}$ and reaction with $O\left({ }^{1} D\right)$ in the stratosphere are comparable. To derive the given loss rates, it was assumed that the initial mixing ratio of the compound was 1 ppbv. The calculated lifetimes and the relative vertical profiles are independent of this assumption.

molecule from the atmosphere.

Our measured absorption cross section for $\mathrm{CF}_{4}$ at the Lyman- $\alpha$ region of the spectrum is nearly an order of magnitude smaller than that reported by Inn (13). We attribute this discrepancy to the possible presence of impurities in his sample even though he vacuum-distilled his sample before use. When we measured the cross section using a $99.7 \%$ pure sample of $\mathrm{CF}_{4}$, we obtained a value of $2.84 \times 10^{-20}$ $\mathrm{cm}^{2}$. However, a purer sample ( $>99.95 \%$ pure) yielded the value reported in Table 1. Sauvageau et al. $(14,15)$ measured the absorption cross sections of various fluorocarbons in the VUV region. Their spectra indicate no absorption $\left(\sigma \leq 3 \times 10^{-19}\right.$ $\mathrm{cm}^{2}$ ) for both $\mathrm{CF}_{4}$ and $\mathrm{C}_{2} \mathrm{~F}_{6}$, in agreement with our values for these two molecules. Doucet et al. (16) reported the absorption cross sections for $\mathrm{CF}_{3} \mathrm{Cl}$ and $\mathrm{CF}_{2} \mathrm{Cl}_{2}$ in the VUV region. Our value for $\mathrm{CF}_{3} \mathrm{Cl}$ agrees with their graphical value if it is assumed that they are reporting the molar extinction to base $e$.

The fate of the excited molecule formed after absorption of Lyman- $\alpha$ radiation has not been experimentally determined. However, on the basis of the continuous nature of these absorptions and the energy available from a Lyman- $\alpha$ photon, we assume that the molecule dissociates. The ionization thresholds for these molecules are larger than the Lyman- $\alpha$ energy. On the basis of energetics, Lyman- $\alpha$ light absorption can lead to production of $\mathrm{F}^{-}$and the companion positive ion; however, such a process also leads to dissociation of the molecule. Hence, absorption of Lyman- $\alpha$ radiation in the at- 
mosphere is assumed to lead to the destruction of the molecule.

\section{Modeling Calculations and Lifetimes}

Our laboratory studies show that the major identified destruction of these perfluorinated species will be confined mostly to the mesosphere and thermosphere (that is, above $\sim 60 \mathrm{~km}$ ). The lifetimes of these species in the atmosphere therefore depend on both photochemistry and atmospheric transport processes, which control the rate of transfer of material to the loss region. We evaluated these processes with a detailed model that couples chemistry and atmospheric transport (17). The model extends from $100 \mathrm{mbar}(\sim 16 \mathrm{~km})$ to the lower thermosphere $(\sim 116 \mathrm{~km})$. It includes a full treatment of the photochemistry of the stratosphere, mesosphere, and lower thermosphere, together with a coupled representation of the influence of gravity wave breaking on the mixing and advection of the middle atmosphere. The model yields seasonal variations in mesospheric temperatures, winds, and concentrations of species such as $\mathrm{O}_{3}$ and thermospheric atomic $\mathrm{O}$ that are in general agreement with observations (17).

In the model calculations, we imposed an initial uniform distribution for the compounds considered here. We ran the model for 10 years, during which time a seasonal steady-state distribution was achieved (that is, the densities of the compounds considered and their lifetimes changed by less than $5 \%$ over the entire model domain compared to the previous year). The resulting lifetimes, $\tau$, attributable to various destruction pathways are shown in Table 2 . Also shown are the fractional contributions of the individual loss processes to the calculated overall lifetime, denoted by $\tau$ (best). It is clear from Table 2 that photolysis at $121.6 \mathrm{~nm}$ (Lyman- $\alpha$ ) contributes significantly to the destruction of all the molecules, except $\mathrm{CF}_{2} \mathrm{ClCF}_{2} \mathrm{Cl}$. For fully fluorinated species, 121.6-nm photolysis is the major loss process. For the CFCs, reaction with $O\left({ }^{1} D\right)$ and UV photolysis are also important. For $\mathrm{SF}_{6}$, some loss may occur as a result of electron attachment (with an adopted reaction rate constant of $10^{-9} \mathrm{~cm}^{3}$ molecule ${ }^{-1} \mathrm{~s}^{-1}$ ) in the mesosphere. We assumed that, upon attachment of electrons by $\mathrm{SF}_{6}$, the molecule is destroyed, even though it is not clear that this is the case. The assumption that electron attachment leads to destruction gives us a lower limit for the lifetime of $\mathrm{SF}_{6}$. Electron attachment to other perfluorocarbons was neglected because the electron affinities of these molecules are negative and thermal electrons will not dissociate them.
As shown in Figs. 1 and 2 for $\mathrm{CF}_{3} \mathrm{CF}_{2} \mathrm{Cl}$ and $\left(\mathrm{CF}_{3}\right)_{2} \mathrm{c}-\mathrm{C}_{4} \mathrm{~F}_{6}$, respectively, the relative loss rates of the molecules vary as functions of altitude. These are relative values only and are intended to represent the shapes of the loss rate profiles rather than their absolute values. The figures also show how the contributions of the three most important loss processes, photolysis at $121.6 \mathrm{~nm}$, reaction with $\mathrm{O}\left({ }^{1} D\right)$, and UV photolysis, vary with altitude and illustrate where in the atmosphere dominant losses occur. Compounds such as the CFCs (for example, CFC-11 or CFC-12) are destroyed mainly between 20 and $40 \mathrm{~km}$, whereas the species considered here decompose in the $80-\mathrm{km}$ range. The figures show that calculation of the lifetimes of these species requires a model that extends to the lower thermosphere.

We did not investigate the individual loss processes for perfluoro $n$-butane $\left(\mathrm{C}_{4} \mathrm{~F}_{10}\right)$, a molecule of current interest, because a sample of this compound was not available. However, on the basis of analogy with other perfluoroalkanes, we estimated the Lyman- $\alpha$ absorption cross section and $O\left({ }^{i} D\right)$ reaction rate coefficients for $\mathrm{C}_{4} \mathrm{~F}_{10}$ (Table 1). For these estimates, the atmospheric lifetime of this compound was calculated (Table 2).

\section{Discussion and Implications}

Reaction with $\mathrm{OH}$. The reaction of these molecules with $\mathrm{OH}$, in either the ground state or the vibrationally excited states, cannot be important and hence has been neglected. The reaction

$$
\mathrm{OH}+\mathrm{CF}_{4} \rightarrow \mathrm{CF}_{3}+\mathrm{HOF}
$$

is endothermic by $78 \mathrm{kcal} \mathrm{mol}^{-1}$. Therefore, excitation of $\mathrm{OH}$ up to at least the

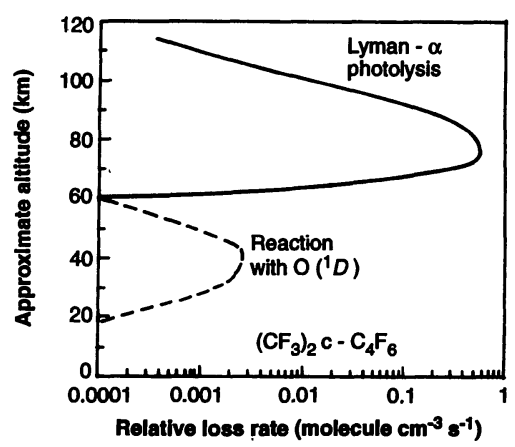

Fig. 2. Relative noontime loss rates at midlatitude in the summer for $\left(\mathrm{CF}_{3}\right)_{2} \mathrm{C}-\mathrm{C}_{4} \mathrm{~F}_{6}$ due to photolysis at $121.6 \mathrm{~nm}$ (solid line) and reaction with $O\left({ }^{1} D\right)$ (dashed line) as functions of altitude. For this molecule, the losses due to 121.6$\mathrm{nm}$ photolysis at $\sim 75 \mathrm{~km}$ dominate over all other processes. To derive the given loss rates, we assumed that the initial mixing ratio of the compound was 1 ppbv. The calculated lifetimes and the relative vertical profiles are independent of this assumption. tenth vibrational level of the ground electronic state is needed for this reaction to be thermodynamically allowed. More importantly, in a reaction in which $\mathrm{OH}$ is abstracting another atom from a molecule, the vibrational excitation of $\mathrm{OH}$ would be inefficient in promoting the reaction. Therefore, the above reaction is likely to be negligible for $\mathrm{CF}_{4}$ and for other perfluorocarbons. In the case of perfluorocarbons, $\mathrm{OH}$ could react by a different route, as shown below for $\mathrm{CF}_{4}$,

$$
\mathrm{OH}+\mathrm{CF}_{4} \rightarrow \mathrm{CF}_{3} \mathrm{O}+\mathrm{HF}
$$

This reaction needs to proceed through a four-centered complex or a more complicated addition followed by rearrangement. We measured the upper limit for the overall reaction of $\mathrm{OH}$ with $\mathrm{CF}_{4}$ to be $<2 \times 10^{-18}$ $\mathrm{cm}^{-3}$ molecule ${ }^{-1} \mathrm{~s}^{-1}$; this complex reaction could not be enhanced by vibrational excitation of $\mathrm{OH}$. Therefore, we conclude that the reaction with $\mathrm{OH}$ is a negligible loss process in the atmosphere.

In addition to the removal pathways that we considered explicitly, the perfluoro compounds could be removed by (i) passage through high-temperature combustors, (ii) lightning, (iii) uptake by soil and plants, and (iv) uptake by oceans. We consider each of these factors separately in what follows.

High-temperature combustors. A fraction of all of the constituents in the lower atmosphere is processed through high-temperature combustors such as power plants, incinerators, and internal combustion engines. (Biomass burning takes place at lower temperatures and, hence, probably will not lead to the removal of the fluorocarbons. Therefore, this process has been neglected.) We can estimate the fraction of the tropospheric constituent that may be destroyed by passing through combustors by knowing the amount of air passing through such systems. This amount can be quantified by the rate of $\mathrm{O}_{2}$ consumption, which is indicated by the $\mathrm{CO}_{2}$ production, as was done in a report by the National Academy of Sciences (18). The current input of $\mathrm{CO}_{2}$ to the atmosphere is $\sim 3$ parts per million by volume (ppmv) per year [deduced from (1) and Boden et al. (19)]. This value translates into an $\mathrm{O}_{2}$ consumption of 4 ppmv per year or a removal rate of $\sim 2 \times 10^{-5} \mathrm{year}^{-1}$. Not all combustors are run with stoichiometric mixtures of fuel and $\mathrm{O}_{2}$; some are run under fuel-lean conditions (that is, there is more $\mathrm{O}_{2}$ in these combustors than is necessary to convert all the $\mathrm{C}$ to $\mathrm{CO}_{2}$ and $\mathrm{H}$ to $\mathrm{H}_{2} \mathrm{O}$ ). Therefore, not all the $\mathrm{O}_{2}$ that passes through a combustor is removed. Assuming that only $20 \%$ of the $\mathrm{O}_{2}$ is used up while all of the constituent of interest is destroyed, we estimate that the removal rate is $1 \times$ $10^{-4}$ year $^{-1}$. Therefore, the shortest life- 
time attributed to combustion is about 10,000 years, and this value would apply to compounds that are completely removed by a single pass through the combustors.

There is evidence for the combustion of perfluorobutanes in flames $(20,21)$. However, $\mathrm{CF}_{4}$ is unlikely to be destroyed as rapidly as the larger fluorocarbons, which can undergo $\mathrm{C}-\mathrm{C}$ bond fission. The main pathway for the destruction of $\mathrm{CF}_{4}$ in a combustor is probably reaction with $\mathrm{H}$ atoms, rather than thermal decomposition, because the main chain-propagating radicals in combustion systems are $\mathrm{OH}, \mathrm{O}$, and $\mathrm{H}$ and the reactions of $\mathrm{OH}$ and $\mathrm{O}$ are much more endothermic than those with $\mathrm{H}$. Considering the concentrations of $\mathrm{H}$ atoms in combustor systems and estimating the rate coefficients for the reaction of $\mathrm{H}$ atoms with $\mathrm{CF}_{4}$, we suggest that less than $10 \%$ of the $\mathrm{CF}_{4}$ would be destroyed in combustion processes. If so, the $\mathrm{CF}_{4}$ lifetime would be $\sim 100,000$ years. Therefore, we place a conservative limit of $>50,000$ years for $\mathrm{CF}_{4}$ loss by combustion (Table 2). The conservative lower limit for the lifetime attributed to combustion for the other molecules we consider would be $>10,000$ years (Table 2 ).

Lightning. Tropospheric constituents may also be removed by lightning. The National Academy of Sciences report (18) also considered the extent of removal of tropospheric constituents by lighting. On the basis of this calculation, the lifetime resulting from this process would be $\sim 1 \times$ $10^{8}$ years. This removal process is so slow compared to the others that we consider it negligible.

Uptake by soil, plants, and ocean. We know of no information on the uptake of perfluoro compounds by living organisms in the soil or by plants. Because all of these molecules contain only C-F bonds, which are much stronger than $\mathrm{C}-\mathrm{H}$ bonds, it is unlikely that they will be taken up to any significant extent. In the case of the CFCs, which are much shorter lived, this process will not contribute. However, the uptake need not be very rapid to affect significantly the lifetime of $\mathrm{CF}_{4}$. On the basis of the analogy with the CFCs (18) and noting that all the compounds considered here are less soluble in water than CFCs, we have not considered loss by uptake into oceans.

The atmospheric lifetimes of the species considered depend not only on the indicated chemical loss processes but also on the transport processes used in the model calculations. Mesospheric chemical destruction can decrease the mixing ratios of gases at high altitudes, thereby decreasing the loss rate and increasing the lifetimes. Observations and model calculation of the densities of water vapor in the mesosphere suggest that its chemical destruction (which depends prominently on photolysis at the Lyman- $\alpha$ region of the spectrum and subsequent photochemistry) is indeed too fast to allow a well-mixed distribution; thus, it is reasonable to expect that the perfluoro compounds examined here should behave similarly. The model-calculated profiles for the perfluoro compounds are essentially well mixed in the stratosphere but decrease at mesospheric altitudes as chemical destruction becomes rapid (see Figs. 1 and 2). We calculated the best estimates of the lifetimes (Table 2) using the processes that we have now identified as loss processes (that is, neglecting the conservative limits for processes that are not quantified) and explicitly calculating mesospheric transport and corresponding vertical gradients for each compound. In addition, we computed lower limits for the lifetimes ( $\tau$ lower limit in Table 2) by assuming that the gradient of the mixing ratios of the molecules above $50 \mathrm{~km}$ is essentially zero (that is, by assuming that the true mesospheric vertical mixing is much faster than that obtained in the model) and combining the calculated lifetimes with that estimated for combustion.

The lifetimes of $\mathrm{CF}_{3} \mathrm{CF}_{2} \mathrm{Cl}$ and $\mathrm{CF}_{2}$ $\mathrm{ClCF}_{2} \mathrm{Cl}$ presented in Table 2 are longer than those reported in earlier studies such as the World Meteorological Organization report (22). This difference is due to the fact that the reaction rate constants for breakdown by $O\left({ }^{1} D\right)$ measured and used here are considerably slower than those adopted in that study. These reactions had not previously been measured in the laboratory, and so the earlier studies were based only on estimates of the rate coefficients. Using the kinetic data presented here, we find that destruction by reaction with $O\left({ }^{1} D\right)$ and photolysis at wavelengths from 180 to 220 $\mathrm{nm}$ dominate the destruction of all these CFCs $\left(\mathrm{CF}_{3} \mathrm{Cl}, \mathrm{CF}_{3} \mathrm{CF}_{2} \mathrm{Cl}\right.$, and $\mathrm{CF}_{2} \mathrm{ClCF}_{2}$ $\mathrm{Cl})$, but photolysis by Lyman- $\alpha$ radiation is significant, especially for $\mathrm{CF}_{3} \mathrm{CF}_{2} \mathrm{Cl}$.

Many of these molecules are rapidly destroyed in the mesosphere. The large absorption cross section for Lyman- $\alpha$ radiation for $\left(\mathrm{CF}_{3}\right)_{2} \mathrm{C}-\mathrm{C}_{4} \mathrm{~F}_{6}$ results in a local lifetime of only a few days for this species near $75 \mathrm{~km}$. However, the atmospheric pressure at this altitude is only about 0.04 mbar; thus, only $2 \times 10^{-5}$ of the Earth's atmosphere lies above this level. Air must therefore cycle through these altitudes some 20,000 times in order to process the entire atmospheric burden. This leads to a lower limit for the atmospheric lifetime of $\sim 800$ years. A short lifetime at these altitudes therefore cannot by itself result in a short overall lifetime for atmospheric species. In the case of molecules whose lifetimes could be $10^{4}$ years or longer, very slow losses at lower altitudes could be important in deter- mining the lifetimes (for example, combustion could play a crucial role in their destruction). Experiments that can determine the extent of destruction, such as the spiking of combustor fuel with fluorocarbons in model systems and measuring their concentrations in the exhaust plume, could be very useful in reducing the uncertainties in the estimated lifetimes for those compounds. Any information on the uptake by soils or plants would also be beneficial.

The lifetimes of various halogenated compounds considered here are very long. The perfluoro compounds have lifetimes of tens of centuries, that is, on the same order of magnitude as human civilization and much longer than the industrial period. The global warming potentials for perfluorocarbons, which depend on their lifetimes, would be very large; probably, much larger than that for CFC-11. Therefore, replacement of CFCs with perfluorocarbons would not diminish the greenhouse forcing in the atmosphere and would be highly likely to increase it substantially over long time horizons. Input of these perfluorocarbons into the atmosphere would lead to their accumulation, and, even if their input were to be curtailed, it would take a long time for the atmosphere to recover to its initial state. The long lifetimes and the possible atmospheric impacts of these compounds are key components of the scientific input to public policy decisions regarding the use of such compounds.

\section{REFERENCES AND NOTES}

1. Intergovernmental Panel on Climate Change (IPCC), Climate Change-The IPCC Scientific Assessment (Cambridge Univ. Press, Cambridge, 1990)

2. D. Wuebbles, private communication.

3. S. A. Penkett, N. J. D. Prosser, R. A. Rasmussen M. A. K. Khalil, J. Geophys. Res. 86, 5172 (1981)

4. M. A. K. Khalil and R. A. Rasmussen, Geophys Res. Lett. 12, 671 (1985)

5. P. Fabian, R. Borchers, B. C. Kruger, S. Lal, J. Geophys. Res. 92, 9831 (1987)

6. C. P. Rinsland, L. R. Brown, C. B. Farmer, ibid. 95, 5577 (1990).

7. R. J. Cicerone, Science 206, 59 (1979)

8. G. Brasseur and S. Solomon, Aeronomy of the Middle Atmosphere (Reidel, Dordrecht, the Netherlands, 1984)

9. R. F. Warren, T. Gierczak, A. R. Ravishankara, Chem. Phys. Lett. 183, 406 (1991).

10. W. B. DeMore et al., Chemical Kinetics and Photochemical Data for Use in Stratospheric Modeling (JPL Publication 90-1, Jet Propulsion Laboratory, California Institute of Technology, Pasadena, 1990)

11. G. L. Vaghjiani and A. R. Ravishankara, J. Chem. Phys. 92, 996 (1990).

12. J. M. Nicovich and A. R. Ravishankara, J. Phys. Chem. 88, 2534 (1984).

13. E. C. Y. Inn, J. Geophys. Res. 85, 7493 (1980).

14. P. Sauvageau, R. Gilbert, P. P. Berlow, C. Sandorty, J. Chem. Phys. 59, 762 (1973)

15. P. Sauvageau et al., ibid. 61, 391 (1974).

16. J. Doucet et al., ibid. 58, 3708 (1973)

17. R. R. Garcia and S. Solomon, J. Geophys. Res. 90, 3850 (1985)

18. Panel on Atmospheric Chemistry, Halocarbons Effects on Stratospheric Ozone (National Acade- 
my of Sciences, Washington, DC, 1976)

19. T. A. Boden, R. J. Sepanski, F. W. Stoss, Trends '91: A Compendium of Data on Global Change (Publ. ORNL/CDIAC-46, Carbon Dioxide Information Analysis Center, Oak Ridge National Laboratory, Oak Ridge, TN, 1991).

20. E. A. Fletcher and D. B. Kittelson, Combust. Flame 12, 164 (1968).

21. L. E. Fuller and E. A. Fletcher, ibid. 13, 43 (1968)

22. Scientific Assessment of Ozone Depletion: 1991 (Global Ozone Research and Monitoring Project-Report 25, World Meteorological Organization, Geneva, 1992).
23. J. H Carver, H. P Gies, T. I. Hobbs, B. R. Lewis D. G. McCoy, J. Geophys. Res. 82, 1955 (1977), and references therein.

24. I. S. Fletcher and D. Husain, J. Phys. Chem. $\mathbf{8 0}$ 1837 (1976).

25. A. P. Force and J. R. Wiesenfeld, ibid. 85, 782 (1981).

26. J. A. Davidson et al., J. Chem. Phys. 64, 57 (1976).

27. R. K. M. Jayanty, R. Simonaitis, J. Heicklen, J. Photochem. 4, 381 (1975)

28. J. N. Pitts, Jr., H. L. Sandoval, R. Atkinson, Chem. Phys. Lett. 29, 31 (1974).

\section{A 100-Year Average Recurrence Interval for the San Andreas Fault at Wrightwood, California}

\section{Thomas E. Fumal, Silvio K. Pezzopane, Ray J. Weldon II, David P. Schwartz}

Evidence for five large earthquakes during the past five centuries along the San Andreas fault zone $\mathbf{7 0}$ kilometers northeast of Los Angeles, California, indicates that the average recurrence interval and the temporal variability are significantly smaller than previously thought. Rapid sedimentation during the past 5000 years in a 150-meter-wide structural depression has produced a greater than 21-meter-thick sequence of debris flow and stream deposits interbedded with more than $\mathbf{5 0}$ datable peat layers. Fault scarps, colluvial wedges, fissure infills, upward termination of ruptures, and tilted and folded deposits above listric faults provide evidence for large earthquakes that occurred in A.D. 1857, 1812, and about 1700, 1610, and 1470.

The next large earthquake on the southern San Andreas fault could affect 10 million people or more in the developed areas of southern California (Fig. 1). Forecasting the time and location of such an event requires an estimate of how often large earthquakes have occurred in the past and the sections of the fault that ruptured during these events. The recurrence times of large earthquakes

T.E. Fumal and D. P. Schwartz are with the U.S Geological Survey, Menlo Park, CA 94025. S. K. Pezzopane and R. J. Weldon are at the University of Oregon, Eugene, OR 97403

Fig. 1. Map of southern California showing major faults (heavy lines) and urban areas (patterned). Locations of paleoseismic sites along the San Andreas fault northeast of Los Angeles are shown as solid circles. Southern part of the 1857 rupture and inferred 1812 rupture are indicated by hatchured lines. Locations of missions active in 1812 are shown as solid squares. The 1812 earthquake was reported at San Diego but not at Santa Barbara; strong shaking was reported at San Buenaventura and San Fernando; damage was most severe at San Gabriel and San Juan Capistrano (17). are most accurately determined from historical records and geologic site investigations of paleoearthquakes. However, sites with
29. D. Gillotay and P. Simon, Aeron. Acta 1988, 336 (1988)

30. We thank F. C. Fehsenfeld, P. Tans, A. F. Tuck, C. J. Howard, and D. L. Albritton for helpful discussions. We are grateful to A.M. Schmoltner, and L. Goldfarb for measuring the upper limit for the $\mathrm{OH}+\mathrm{CF}_{4}$ rate constant and to $\mathrm{R}$. $\mathrm{K}$. Talukdar for help with the $O\left({ }^{1} D\right)$ rate co-efficient measurements. We thank Du Pont for supplying pure samples of some of the compounds used in this study. This work was funded in part by the National Oceanic and Atmospheric Administration under the Global Change Program.

well-dated records of more than a few events are rare. For the southern San Andreas fault, Pallett Creek (Fig. 1) has been the best documented site; it records 12 events since about the early second century A.D. (1-3). From a single site, though, it is impossible to evaluate the length of rupture for individual events or completeness of the earthquake record. These uncertainties are best answered by studying additional paleoseismic sites. Although some data are available from Cajon Creek (4) and Indio (5), neither of these sites has recorded as many events as the Pallett Creek site nor are the events as precisely dated. In this article we present the most recent 500 years of a paleoseismic record comparable to and potentially longer than that at Pallett Creek from near the town of Wrightwood (Fig. 1). This site contains evidence for 12 large earthquakes during the past 1300 years (6-9); we discuss the evidence for the latest five events at Wrightwood, which are the most precisely dated.

Stratigraphy and structure. Our paleoseismic site is located where the active traces of the San Andreas fault zone (SAFZ) cross Swarthout Creek and a small tributary, Government Canyon, $3 \mathrm{~km}$ northwest of Wrightwood (Fig. 2). Two

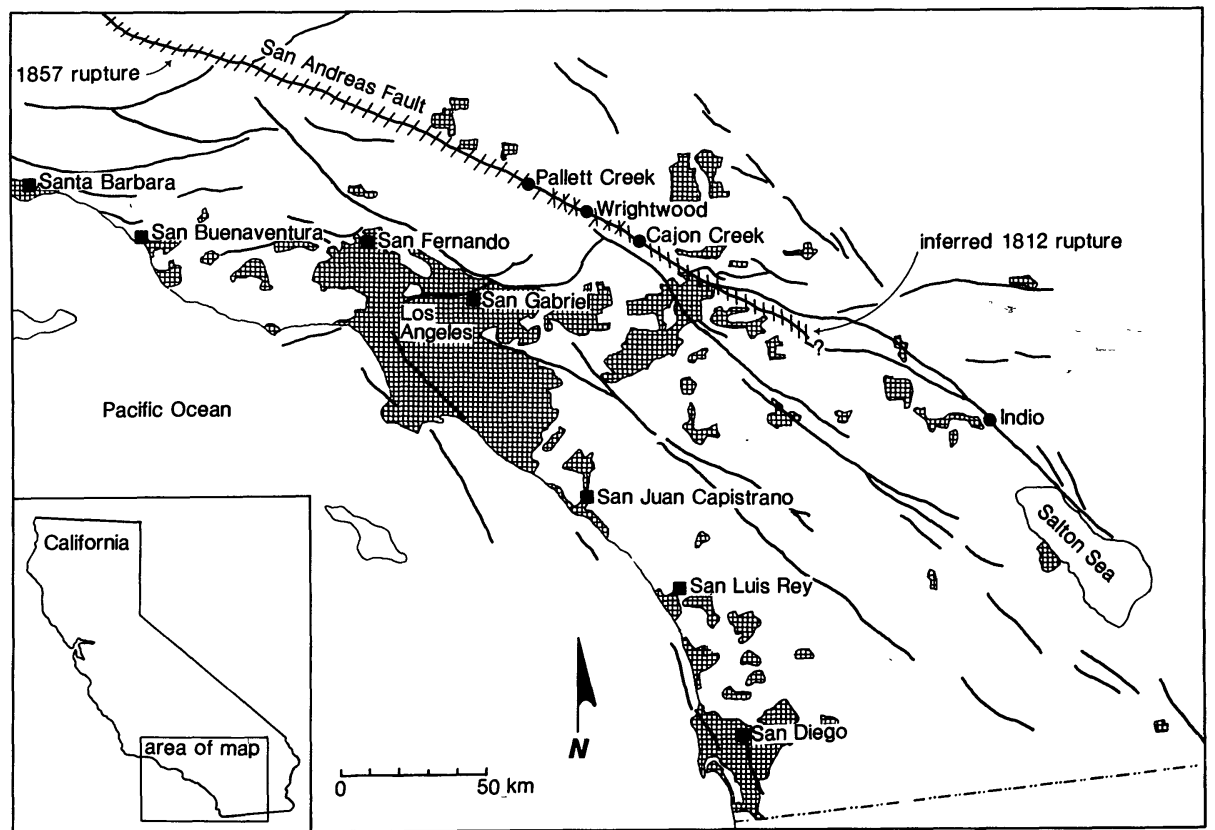

